\title{
Something's Got to Give: A Description of Contemporary Nursing Students
}

\author{
Catharine Maureen Critz, Hobie Etta Feagai \\ College of Nursing and Health Sciences, Hawaii Pacific University, Hawaii, USA \\ Email: ccritz@hpu.edu, hfeagai@hpu.edu
}

Received 19 November 2013; revised 26 January 2014; accepted 8 February 2014

Copyright (C) 2014 by authors and Scientific Research Publishing Inc.

This work is licensed under the Creative Commons Attribution International License (CC BY). http://creativecommons.org/licenses/by/4.0/

cC) (i) Open Access

\begin{abstract}
Objective: The purpose of this study was to explore and describe the socio-demographic profiles, academic habits, and lived experiences of baccalaureate nursing students at a private university in Hawaii. Methods: A mixed method design of descriptive statistics and analysis was used. For this study, a semi-structured, twenty-five item survey was developed by the researchers and reviewed by other faculty for veracity. A convenience sample included level one (LV1) students ( $n=91)$ and level five (LV5) students $(n=64)$ attending class on the day of the survey. Results: Analysis revealed that contemporary students have complex lives with multiple work, family, financial, program, and health challenges that impact their lives as students. The majority of students in this sample were identified as Asian or Pacific Islander. Fifty percent of students in both levels worked 20 hours per week and about $1 / 4$ in both levels had children. About $25 \%$ spent more than 15 hours per week on social media and studied 1 - 2 hours per day. Fourteen percent of both levels reported getting less than five hours of sleep. Beginning students identified time management and work as the top two barriers to success. Those completing the program identified issues with the nursing program and family obligations. Conclusions: Factors identified in this study not only impact students' performance in the classroom but also have implications for performance in the clinical areas. These factors suggest that nursing faculty take into consideration the perceived needs of students while maintaining ethics and high academic standards. The understanding gained from this study will inform curriculum revision and program development.
\end{abstract}

\section{Keywords}

Nursing Students; Nursing Education; Barriers

\section{Introduction}

Nursing education at the baccalaureate level is very often not the only concern for a student. Various life expe- 
riences and concomitant challenges may threaten their academic success. Non-academic struggles of daily life may "compete with the time and effort necessary to be a nursing student" [1]. Sometimes life just gets in the way.

While faculty are often apprised of core demographics, there is little understanding of the day-to-day lived experience of a nursing student and what barriers are present to prevent them from being successful. For example, faculty are unaware of how many students have children (how many and what ages), have deployed spouses, or are in the military themselves. Many students are single parents, live with parents, provide care for parent(s) or grandparents, or are employed either part- or full-time. Do students have health issues that impact learning? The actual amount of time spent studying, relaxing, and sleeping is unknown. Answers to questions such as these will help faculty and administrators better develop academic programs that consider the life balance of students while maintaining high academic standards.

There has been little investigation of the lives of cultural-minority nursing students both inside and outside the classroom milieu. This research study queried students from a moderate-sized, four-year, baccalaureate nursing program at a private university in Hawaii about their lives and their perceived barriers to educational success. The population queried was known to include a high percentage of cultural-minority students. An extensive literature search surrounding these issues revealed limited research studies of culturally diverse, minority nursing students. No studies addressing more global issues about the day-to-day experience of nursing students in school or at home were located although much research related to the stress encountered in a nursing program is available.

Competitive admission criteria, waitlists, rigorous prerequisites, high tuitions, and the challenging economy only begin the stress of nursing school [2]. Nursing students traditionally experience extremely longer hours of study and time spent in the clinical area, which impedes the amount of free time for other things important to them. Quite simply, nursing students are reported being "tired and exhausted" [3]. Major stressors identified in the literature affecting both school performance and personal well-being are: academic rigor, such as assignments/ exams, feeling overworked or unprepared, grades; financial burden; and, interference with daily life including difficulty balancing home and work or meeting conflicting demands [1] [4]-[11]. In response, Colleges of Nursing are exploring innovative and creative ways to be more student-friendly while maintaining high academic standards with an understanding that both recruitment of new students and retention of current students are critical.

Meeting the needs of students is a high priority; but, do the decision-makers really understand the lived experience of these students? The age gap between students and faculty raises interesting questions as colleges of nursing try to tailor programs to meet students' needs. Whereas the average age of a baccalaureate nursing student is now 22 [12], nursing faculties across the country are aging. According to a report published by the American Association of Colleges of Nursing [13], the mean age of doctorate-prepared faculty was 56.3 years and 55 years for master's-prepared faculty. This suggests that faculty may be out of touch with the experience of contemporary students. As faculty try to address these and other issues, through curriculum revision, utilization of technology, and offering courses both at different times and in alternative formats, these experiences will need to be considered.

\section{Methods}

\subsection{Purpose}

The purpose of this study was to explore and describe the socio-demographic profile, academic habits, and lived experiences of level one (LV1) and level five (LV5) nursing students at a private university in Hawaii to better understand the reality of their lives. The understanding gained from this study will inform curriculum revision and program development in alignment with the American College of Colleges of Nursing (ACCN) Essentials of Baccalaureate Education for Professional Nursing Practice to meet the needs of the student population, and improve student success.

\subsection{Data Collection}

At this college of nursing, five semesters are needed complete the program after finishing prerequisite courses. Level one (LV1) begins in the first semester of the junior year. Level five (LV5) is the last semester of this cur- 
riculum as the student prepares to graduate. An application to the university's Institutional Review Board to conduct research on human participants was submitted and approved. A convenience sample included LV1 students $(n=91)$ and LV5 students $(n=64)$ attending class on the day of the survey. The students were verbally given information about the study and asked to voluntarily participate. Each participant signed an informed consent form assuring confidentiality and anonymity. A mixed methods approach was used. A semi-structured, twenty-five item survey was developed by the researchers and reviewed by other faculty for veracity. Forcedchoice answers were analyzed using descriptive statistics, while comments and open-ended questions were analyzed using descriptive content analysis. The paper and pencil survey was administered in one sitting by the researchers. Students were given about 20 minutes of approved class time in February, 2012, to complete the questionnaire. Grades or class standing were not affected if students chose not to participate.

\section{Results}

\subsection{Basic Demographics}

Student ages and gender varied between levels (see Tables 1 and 2). LV5 students were generally older than LV1 students even though just one academic year separated the groups. The majority of students identified themselves as Asian (see Table 3).

\subsection{Family Life}

Living arrangements varied among levels. A majority of LV1 (65\%) lived at home, while many lived independently with a partner or significant other (LV1 21\%). Eight percent of LV1students reported living with other college students. Only 2\% of LV1 students lived alone and only 1\% of LV1 students resided in the university dormitory. Three percent of LV1 students described other living situations, such as living with cousins, boyfriend's parents, or boyfriend's sister. Forty eight percent of LV5 students lived at home, $42 \%$ with a significant other, $6 \%$ lived independently, $1 \%$ with other college students, and 3\% described other living situations.

Twenty four percent of LV1 students were married compared to 39\% of LV5 students. Among LV1 students, $16 \%$ were cohabitating with same or opposite sex partners while $9 \%$ of LV5 students were cohabitating. The remaining students (LV1 60\%; LV5 52\%) identified as being single.

Twenty three percent of LV1 students and 36\% of LV5 students had children. Most students reported two children (range 1 - 4 children). Eight students had children under the age of two years and nine students had teenagers. For the levels combined the range of age of children reported was newborn to age 30 . With the exception of two LV5 students, all of the children lived full-time with the student. Caretaking was accomplished for both groups by a combination of parents, grandparents, and other caregivers or by taking classes while the children were in school.

\subsection{Health}

Eighty-five percent of LV1 students described themselves as healthy, while 87\% of LV5 students reported no health issues that impacted school success. The remainder of student respondents (LV1 15\%; LV5 13\%) described a variety of sporadic health issues impacting academic success including pregnancy, cardiac problems, migraine headaches, depression, asthma, insomnia, chronic pain, and diabetes. The majority of both LV1 and LV5 students reported getting very little sleep. Sleep, an important component of health and well-being, is outlined on Table 4.

\subsection{Work}

Nearly one-half of students in both LV1 and LV5 reported working (51\% \& 50\% respectively). The range of work hours was 4 to 40 hours per week. Of this group, 30\% of both LV1 and LV5\% students worked more than 20 hours per week. Level-one students worked, on average, more hours than LV5 students (19.25 hours vs. 17.2 hours). Among LV1 students $16 \%$ worked in the health care field in roles such as certified nurse assistant (CNA), registered nurse, receptionist, office staff, and hospital patient advocacy. Eighteen percent of LV5 students were employed in the health care field (medical office assistants, CNA's, ER scribe, nurse aid, or technicians). Table 4 contrasts work hours, study hours, and time spent on social media per week. 
Table 1. Basic demographics-age.

\begin{tabular}{ccc}
\hline Age in Years & Level One & Level Five \\
\hline $18-25$ & $58 \%$ & $30 \%$ \\
$26-30$ & $19 \%$ & $45 \%$ \\
$31-35$ & $18 \%$ & $16 \%$ \\
$36-40$ & $5 \%$ & $3 \%$ \\
over 40 & $0 \%$ & $6 \%$ \\
\hline
\end{tabular}

Table 2. Basic demographics-gender.

\begin{tabular}{ccc}
\hline Gender & Level One & Level Five \\
\hline Female & 79 & 90 \\
Male & 19 & 9 \\
Transgender & 2 & 1 \\
\hline
\end{tabular}

Table 3. Race to which students most identify.

\begin{tabular}{ccc}
\hline & Level One & Level Five \\
\hline Asian & $69 \%$ & $53 \%$ \\
Pacific Islander & $10 \%$ & $13 \%$ \\
Black & $1 \%$ & $3 \%$ \\
Caucasian & $16 \%$ & $25 \%$ \\
Hispanic & $3 \%$ & $5 \%$ \\
Other & $1 \%$ & $1 \%$ \\
\hline
\end{tabular}

Table 4. Comparison of work, study, \& social media hours per week.

\begin{tabular}{|c|c|c|}
\hline & Level One & Level Five \\
\hline Percentage of students working & $51 \%$ & $50 \%$ \\
\hline Average number of hours worked per week & 19.25 & 17.2 \\
\hline \multicolumn{3}{|l|}{ Hours Spent Studying } \\
\hline • 1 - 5 hours & $8 \%$ & $10 \%$ \\
\hline • 6 - 10 hours & $33 \%$ & $30 \%$ \\
\hline - 11 - 15 hours & $28 \%$ & $24 \%$ \\
\hline - 16 hours or more & $31 \%$ & $36 \%$ \\
\hline \multicolumn{3}{|l|}{ Hours spent on social media } \\
\hline - 7 hours or less & $51 \%$ & $46 \%$ \\
\hline - 8 - 14 hours & $25 \%$ & $34 \%$ \\
\hline • 15 - 21 hours & $13 \%$ & $13 \%$ \\
\hline • 22 - 28 hours & $8 \%$ & $6 \%$ \\
\hline - More than 28 hours & $3 \%$ & $1 \%$ \\
\hline Percentage of students with children & $23 \%$ & $36 \%$ \\
\hline \multicolumn{3}{|l|}{ Hours of Sleep } \\
\hline - Less than 5 hours & $14 \%$ & $14 \%$ \\
\hline - 5 - 6 hours & $63 \%$ & $51 \%$ \\
\hline - 7 or more hours & $23 \%$ & $35 \%$ \\
\hline
\end{tabular}

\subsection{Student Life}

Both LV1 and LV 5 students identified studying and working as consuming most of their time. LV1 students put 
far less time into studying than did LV5 students (see Table 4).

On campus, students have timely access to resource centers where assistance is readily available. LV1 students spent an average of 3.23 hours per week in the library, with a range of 0 - 16 hours per week, while LV5 students spent 3.3 hours in the library at a range of $0-10$ hours per week. Use of the educational technology center (computer lab) was higher among LV1 students who spent an average of 2.26 hours per week (range 0 10 hours) while LV5 students spent only 0.8 hours per week (range $0-3$ ).

Students seeking help from professors varied by level. Interestingly, 27\% of LV1 students and 13\% of LV5 students indicated seeking no assistance at all from professors. Fifty four percent of LV1 and 52\% of LV5 students reported requesting 1 - 2 hours of professor assistance. Fourteen percent of LV1 student and 19\% LV5 students requested 2 - 3 hours of support per week. More than 4 hours of assistance per week were requested by $5 \%$ of LV1 students and $16 \%$ of LV5 students.

When asked to identify the learning format that works best for them, LV1 students identified lecture as most popular (53\%), while only $2 \%$ identified on-line learning as their preferred format. LV1 students indicated that professors "reading PowerPoint slides" was the least effective format for learning. LV5 students identified lecture as the most preferred format (20\%) and on-line learning as equally preferred (20\%). Five percent of LV5 students preferred small group discussion.

In the comments section for preferred learning format, students indicated a preference for "a combination of lecture and small group discussions," "a combination of online learning and lecture," "simulation laboratory experience," "engaging teachers," and "hands-on/clinical experiences” as their most preferred learning format.

\subsection{Social Life}

The social life of nursing students was constricted. Fifty and 53\% of LV1 and LV5 students respectively reported spending just 0 - 2 hours per week with friends. Social media use was significant for both LV1 and LV5 students with only one student in the entire sample reporting no social media use. The range of use for both groups was 7 - 28 hours per week. Three quarters of students used 1 - 14 hours of social media per week. Social media use during class time was also reported. Fifty-one percent of LV1 students and 35\% of LV5 students reported never using social media in class. Thirty percent of both LV1 and LV5 students used social media between 1 - 4 minutes. Eight percent of LV1 and 7\% of LV5 students reported using social media in class between 10 to over 20 minutes (see Table 4).

\subsection{Barriers to Success}

Students were asked, “What barriers prevent you from being a successful student?” The open-ended answers clustered around four main themes for both groups: 1) time management, 2) work, 3) family obligations, and 4) academic issues. Many students listed more than one barrier. Only 50 LV1 students responded to this openended question. Level one students identified time management as the main barrier to success (32\%). Other barriers included work (14\%); family obligations, such as caring for children, caring for parents, "being a wife" and "home responsibilities" (13\%); procrastination (9\%); distractions at home (3\%); and, financial problems (4\%). Additional concerns included difficulties with the program itself (16\%). Examples of concerns include:

- "Exams being too difficult"

- "Expectations not clear"

- "Too many classes in one semester"

- "Overload of irrelevant material"

Although LV 5 students also identified family/children obligations (24\%); time management (20\%); work responsibilities (16\%); financial barriers, such as ability to pay parking, for food, and rent (12\%); and, travel time to school (5\%), they also voiced double the amount of concerns with the program itself (30\%). Examples of comments included

- A 25+ page epidemiology paper required in the last semester of the nursing program was cited by several students as "taking up too much time" and "a waste of time"

- "Overwhelming work load" and "too much paperwork"

- "Too many assignments, not enough time to sleep"

- "Long clinical hours"

- "Not enough clinical hours" 
- "Communication problems, professors who have English as a second language"

- "Unclear course objectives"

- "Lack of communication between professors"

- "Curriculum that is insufficiently aligned with pertinent NCLEX information"

- "Teachers expecting you to know everything".

\subsection{Level Five Student Strategies for Success}

One of the goals of this research study was to identify what lifestyle changes nursing students made from LV1 to LV5 to improve their success in the nursing program (Table 4). Most students responded with more than one answer. Examples of responses included:

- Decreasing time spent socializing with friends

- Sacrificing family time

- Learning how to better manage time

- Reducing work hours

- Changing strategies for improved learning (including accessing professors more often, studying individually rather than in groups, reading more, taking better notes, and reviewing taped or narrated lectures)

- Engaging in stress reduction and health promotion activities such as "getting more (or less) sleep," "eating better," "drink more coffee", "exercising," and "quitting smoking".

\section{Discussion}

Understanding the lives of students is a unique way for the faculty and staff of baccalaureate nursing programs to better meet the needs of their students. The lives of both beginning and students nearing graduation are complex. Unlike the college experience of traditional nursing faculty now in their mid-to-late 50's when nursing students went to school full-time, lived in the university dormitory or roomed with other nursing students, and immersed themselves in the nursing school experience, the life of contemporary nursing student is considerably different. Up to one-half of the students surveyed in this study worked an average of 20 hours per week, had family obligations including children to care for, had limited time with friends, and reported getting very little sleep.

\subsection{Demographics}

The student body in this sample is culturally different compared to national statistics which suggests that findings may not generalize to other programs. Baccalaureate nursing programs, according to the AACN 2012 report, indicates the following breakdown in enrollment: White-72\%; Hispanic or Latino-7\%; Black or African Americans-10.3\%; Asian/Native Hawai'i an/other Pacific Islanders- $8.8 \%$. Thus, the culturally diverse, minority enrollment of nursing students at this university is inversely proportional to the national norm. Faculty who misunderstand or do not consider a student's culture has been identified as a source of stress for some students [14].

\subsection{Family Life}

Local cultural and economic constraints have an impact on the lives of students at this university. A majority of the LV1students lived at home while nearly one-half of LV5 were living at home. This is in part due to island life where distance to school is not immense, the high cost of living in Hawaii, and the local cultural norm of living in multigenerational households. Students in this program may, therefore, have different experiences from those in other mainland programs. While students may have more financial and emotional support living at home, other stressors such as caring for grandparents and household responsibilities were identified as barriers to success. Future research might address the difference between the lived experiences of those nursing students living at home and those living away from home.

One impetus for this study was a startling realization by the researchers that many of the students had children. About one quarter of these students had one to four children. Pryjmachuk \& Richards [9] showed an increase in personal problems when students had preschool or school-age children at home. The demands of caring for 
young children on top of meeting academic and work demands were "overwhelming” for some students. While having students who are parents often brings a rich discussion in the classroom, understanding the needs of these parents may need to be taken into consideration when making assignments and developing group projects. Building time into courses for students to meet for group projects, rather than expecting students to meet outside of class, helps not only students with children but also all students who travel distances to school or have other family demands and work obligations. The need for gathering places at a university is, therefore, important.

\subsection{Health}

An alarming finding in this study was related to student health. Although over $80 \%$ of students in both levels identified themselves as being healthy, lack of sleep permeated both groups. Fourteen percent of students reported getting less than five hours of sleep per night while approximately $50 \%$ of students reported getting 5 - 6 hours of sleep. Sleep deprivation has a negative impact on personal and professional lives, learning ability, and puts both nurses and their patients in jeopardy [15] [16]. Neuro-behavioral deficits in attention, memory, and psychomotor speed have been noted [15] as have the impact of driving while sleep deprived. Schools of medicine have addressed this issue in residency training requirements; however, no such guidelines have been developed for nursing students in clinical placements. Students must perform at high levels in both the classroom and in the clinical area, which is undermined by sleep deficits. Sleep deprivation must be considered as faculties strive to strike a balance between demands of the program and safety for student nurses and their patients.

\subsection{Work}

About one half of students in this total sample reported working at least 20 hours per week. Struggling students are often those who have too many obligations outside of being enrolled in a nursing program. Job stress has been identified as an additional stressor for the student working while in nursing school [4]. Although faculty frequently discuss work obligations as problematic for nursing students, one cannot ignore the financial burden many students carry. Interestingly, LV5 students identified decreasing work hours as one of their strategies for success. This is a message that needs to be passed down to LV1 students.

\subsection{Social Life}

Finding the appropriate balance between meeting school demands and having a social life appears to be one of the key factors for student success. Giving up some social activities with both family and friends was the most identified strategy for academic success by LV 5 students. This strategy has controversial implications as family and friends are often the student's strongest support systems.

Although students reported "giving up" their social life, nearly $75 \%$ in both levels reported spending at least 7 - 14 hours per week on social media with some spending as much as 28 hours per week. Utilizing technology as a way of staying connected with friends and family while meeting the demands of a nursing program appears to be a strategy for students. Whether or not this is a positive strategy for academic success merits further research.

The issue of accessing social media for personal use during class time warrants further investigation. Approximately $30 \%$ of students at both levels used between 1 - 5 minutes of social media during class with $7 \%$ $8 \%$ of students spending between 10 - 20 minutes during class. This personal use of technology can be distracting for other students, hinders learning, and can be seen by some as disrespectful. Since many students care for children, parents, and grandparents, asking students to turn off phones/texting during long classes can be irresponsible. Balancing the needs of students while maintaining a "no use other than emergency" policy, while preferential, is impossible to enforce. This is an area, which will likely gain increasing attention over time, and school policies may emerge.

\subsection{School Life}

At both levels over one-half of the students reported studying between 6 - 15 hours per week while 30\% - 35\% studied more than 16 hours per week. Given the demands of a rigorous nursing curriculum $1-2$ hours per day is not adequate. Consideration must be given to what and how students are studying. Since lack of time management was identified as the greatest barrier to success, helping students learn how to prepare for class, critically 
think, and sit for exams are areas ripe for intervention.

Use of the library was similar for both groups, however LV1 Students spent more time in the computer lab. Level five students may have had more access to personal computers which would account for some of the differences. These sites are gathering places for students where work space, computers, printers, and large tables are available as well as valuable resources. Many students on this campus use outdoor gathering areas as well. These areas are important for students to study on long days on campus and it frees students from home distractions.

A rather surprising finding was the fact that $25 \%$ of LV1 students reported seeking no help from faculty over the course of the semester. Unfortunately, this survey did not ask why. This finding suggests that faculty need to be more proactive in connecting with LV1 students, such as through mentoring, more flexible office hours, and generally indicating an open willingness to provide a contact with faculty. Although working directly with faculty was not identified as a strategy for success, it appears that as students move through the program they feel more comfortable seeking help from faculty.

Students in this study identified workload as one of the many barriers to their success. Students often feel that the structure and academic rigor of courses fails to take into consideration their need for a work/life/family balance and culturally diversity [5] [10]. Some students admitted to lowering their standards as a time-saver especially for the older student. Faculty must maintain the balance of presence and caring with nursing students while keeping a professional relationship of sound ethics and academic standards. Curricula may be examined for areas of academic overload, potentially too demanding biopsychosocially, that will negatively impact the learning and personal growth required of culturally—diverse nursing students [6] [17].

\subsection{Barriers to Success}

The beginning students in this study clearly identified time management and procrastination as key barriers to their education. They also reported feeling overwhelmed with the amount of work in LV1 courses. The nontraditional-age student with children says "their time is their most valuable commodity... one of the most important skills they've learned is the art of multitasking by incorporating the whole family in their school projects” [17]. These findings suggest that courses with clear structure and timelines for assignments is essential in early courses and that level faculty need to communicate with each other about the amount of work being assigned. The number of courses with limited credit also needs to be critically reviewed. Further, teaching time management skills early in the process may be very helpful.

Programmatic issues were the priority barrier identified by LV5 students. Academic program barriers can and should be clearly identified so that faculty can address those issues in a formal, systematic, yet expedient manner. Students themselves suggested that faculty need to work together within each of the five levels of the nursing program looking at exam schedules and assignments to determine if the overall level workload is appropriate and realistic. Students also identified family obligations and financial constraints as barriers to nursing program success. Innovative university approaches, such as providing on-site day care services, Nurse Practitioner-run health care clinics, and financial guidance services, may go a long way in easing student stress and improving student retention rates.

\section{Conclusion}

This study suggests that the lived experience of nursing students today is complex and demanding. Approximately one quarter of these nursing students had children, and one half worked as long as 20 hours per week. The students identified constricted social lives, poor time management skills, and significant lack of sleep. About one third studied only 6 - 10 hours per week and about one quarter spent 8 - 16 hours per week on social media. Over one quarter of level-one students were reported never seeking help from instructors, whereas over one half of level-five students sought help. These factors, areas for future research, not only impact performance in the classroom but have strong implications for performance in the clinical area as well. These factors suggest that while nursing faculty take into consideration the perceived needs of students, maintaining ethics and high academic standards is essential to securing professional competency for students. The understanding gained from this study will inform curriculum revision and program development in alignment with the American College of Colleges of Nursing (ACCN) Essentials of Baccalaureate Education for Professional Nursing Practice to meet the needs of the student population and improve student success. 


\section{Limitations}

Limitations to this study include the small sample size and being conducted as a single-sited study. The impact of being confined to a cultural minority group in the middle of the ocean could be seen as another limitation.

\section{References}

[1] Poorman, S.G., Mastorovich, M.L. and Webb, C.A. (2002) Helping Students Who Struggle Academically: Finding the Right Level of Involvement and Living with Our Judgments. Nursing Education Perspectives, 32, 369-374. http://dx.doi.org/10.5480/1536-5026-32.6.369

[2] Goff, A. (2011) Stressors, Academic Performance, and Learned Resourcefulness in Baccalaureate Nursing Students [Electronic Version]. International Journal of Nursing Education Scholarship, 8, 1-15. http://dx.doi.org/10.2202/1548-923X.2114

[3] Gibbons, C., Dempster, M. and Moutray, M. (2007) Stress and Estress in Nursing Students. Journal of Advanced Nursing, 61, 282-290. http://dx.doi.org/10.1111/j.1365-2648.2007.04497.x

[4] Clark, C.S. and Pelicci, G. (2011) An Integral Nursing Education: A Stress Management and Life Balance Course. International Journal for Human Caring, 15, 13-22.

[5] Gibbons, C., Dempster, M. and Moutray, M. (2011) Stress, Coping and Satisfaction in Nursing Students. Journal of Advanced Nursing, 67, 621-632. http://dx.doi.org/10.1111/j.1365-2648.2010.05495.x

[6] Jimenez, C., Navia-Osorio, P.M. and Diaz, C.V. (2009) Stress and Health in Novice and Experienced Nursing Students. Journal of Advanced Nursing, 66, 442-455. http://dx.doi.org/10.1111/j.1365-2648.2009.05183.x

[7] Jones, M.C. and Johnston, D.W. (1997) Distress, Stress and Coping in First Year Nursing Students. Journal of Advanced Nursing, 26, 475-482. http://dx.doi.org/10.1046/j.1365-2648.1997.t01-5-00999.x

[8] Magnussen, L. and Amundson, M.J. (2003) Undergraduate Nursing Student Experience. Nursing and Health Sciences, 5, 261-267. http://dx.doi.org/10.1046/j.1442-2018.2003.00158.x

[9] Maville, J.A., Kranz, P. and Tucker, B.A. (2004) Perceived Stress Reported by Nurse Practitioner Students. Journal of the American Academy of Nurse Practitioners, 16, 257-272. http://dx.doi.org/10.1111/j.1745-7599.2004.tb00448.x

[10] Pryjmachuk, S. and Richards, D.A. (2007) Predicting Stress in Pre-Registration Nursing Students. British Journal of Health Psychology, 12, 125-144.

[11] Watson, R., Gardiner, E., Hogston, R., Gibson, H., Stimpson, A., Wrate, R. and Deary, I. (2008) A Longitudinal Study of Stress and Psychological Distress in Nurses and Nursing Students. Journal of Clinical Nursing, 18, 270-278.

[12] Black, B. (2014) Professional Nursing: Concepts and Challenges. 7th Edition, Elsevier, St. Louis.

[13] American Association of Colleges of Nursing (2012) Report on 2010-2011 Salaries of Instructional and Administrative Nursing Faculty in Baccalaureate and Graduate Programs in Nursing. http://www.aacn.nche.edu/IDS

[14] Callister, L., Khalaf, I. and Keller, D. (2000) Cross-Cultural Comparison of the Concerns for Beginning Baccalaureate Nursing Students. Nurse Educator, 25, 267-269. http://dx.doi.org/10.1097/00006223-200011000-00007

[15] Lally, R. (2009) Badge of Honor or Recipe for Disaster? The Importance of Adequate Sleep for Nurses. Oncology Nurses Society Connect, 24, 8-12.

[16] Olson, E., Drage, L. and Auger, R. (2009) Chest, Sleep Deprivation, Physician Performance, and Patient Safety. The American College of Chest Physicians, 136, 2. http://dx.doi.org/10.1378/chest.08-1952

[17] Dunham, K.S. (2011) Chapter 6: Yes, You Can Avoid Fatigue Related to Being Perceived as “Different”. In: Davis, F.A., Ed., How to Survive and Maybe Even Love Nursing School, Philadelphia, 119-133. 